\title{
BMJ Open Hospital physicians' views on discharge and readmission processes: a qualitative study from Norway
}

\author{
Malin Knutsen Glette, ${ }^{\oplus 1,2}$ Tone Kringeland, ${ }^{1}$ Olav Røise, ${ }^{2,3,4}$ Siri Wiig ${ }^{2}$
}

To cite: Knutsen Glette M, Kringeland T, Røise 0 , et al. Hospital physicians' views on discharge and readmission processes: a qualitative study from Norway. BMJ Open 2019;9:e031297. doi:10.1136/ bmjopen-2019-031297

- Prepublication history and additional material for this paper are available online. To view these files, please visit the journal online (http://dx.doi. org/10.1136/bmjopen-2019031297).

Received 26 April 2019 Accepted 09 August 2019

A) Check for updates

(C) Author(s) (or their employer(s)) 2019. Re-use permitted under CC BY-NC. No commercial re-use. See rights and permissions. Published by BMJ.

${ }^{1}$ Department of Health and Caring Sciences, Western Norway University of Applied Sciences - Haugesund Campus, Haugesund, Norway

${ }^{2}$ Faculty of Health Sciences, SHARE - Centre for Resilience in Healthcare, University of Stavanger, Stavanger, Norway ${ }^{3}$ Institute of Clinical Medicine, University of Oslo, Oslo, Norway ${ }^{4}$ Division of Orthopedic Surgery, Oslo University Hospital, Oslo, Norway

Correspondence to

Malin Knutsen Glette;

Malinknutsen.glette@hvl.no

\section{ABSTRACT}

Objectives To explore hospital physicians' views on readmission and discharge processes in the interface between hospitals and municipalities.

Design Qualitative case study.

Setting The Norwegian healthcare system.

Participants Fifteen hospital physicians (residents and consultants) from one hospital, involved in the treatment and discharge of patients.

Results The results of this study showed that patients were being discharged earlier, with more complex medical conditions, than they had been previously, and that discharges sometimes were perceived as premature. Insufficient capacity at the hospital resulted in pressure to discharge patients, but the primary healthcare service of the area was not always able to assume care of these patients. Communication between levels of the healthcare service was limited. The hospital stay summary was the most important, and sometimes only, form of communication between levels. The discharge process was described as complicated and was affected by healthcare personnel, by patients themselves and by aspects of the primary healthcare service. Early hospital discharges, poor communication between healthcare services and inadequacies in the discharge process were perceived to affect hospital readmissions.

Conclusion The results of this study provide a better understanding of hospital physicians' views on the discharge and hospital readmission processes in the interface between the hospital and the primary healthcare service. The study also identifies discrepancies in governmental requirements, reform regulations and current practices in municipalities and hospitals.

\section{BACKGROUND}

Hospital readmissions are a well-known problem in healthcare services worldwide ${ }^{1-5}$ with the hospital discharge process as an influential factor. ${ }^{6-8}$ Hospital discharge procedures play a critical role in the quality of transitional care, specifically on the continuity of information about patients' treatments, or recommendations for further care. ${ }^{6}$ Hospital discharges require communication and coordination among stakeholders and multidisciplinary teams within a hospital, and often communication and coordination with stakeholders in a primary healthcare service,

\section{Strengths and limitations of this study}

This study, to our knowledge, is the first to explore hospital physicians' views on readmissions from the primary healthcare service to the hospitals.

- The sample consists of fellows and residents from several specialties within the surgical and medical fields, providing diverse perspectives on the addressed issues.

- The inclusion of a larger sample of physicians from additional medical specialties, as well as other healthcare personnel, patients and their next of kin, would have provided valuable insights into the issues identified in this study.

such as nursing home personnel, homecare personnel and general practitioners (GPs). ${ }^{9}$ Further, the discharge process involves several steps, ${ }^{10}$ starting with the hospital admission, and ending when the patient goes home or to another healthcare facility (figure 1 ). The literature has described the transition from the hospital to other healthcare services as prone to error and accompanied by a risk of adverse events, such as uncoordinated care and hospital readmissions. ${ }^{6} 1112$

In 2018, readmission rates varied from $11.8 \%$ to $18 \%$ in Norwegian hospitals. ${ }^{4}$ A reduction in readmission rates and the implementation of well-coordinated transitions between healthcare services have been common goals of Norwegian healthcare services. Reducing readmission rates and coordinated transitions are also overall aims of the Norwegian Ministry of Health and Care Services in terms of the quality of services offered and guaranteeing patient safety. ${ }^{13-15}$ This became particularly evident after the introduction of an extensive health reform (the Coordination reform) in the Norwegian healthcare service in 2012. The reform has led to changes, such as shorter hospital stays, increased pressures on primary healthcare services and a suspected increase in readmission rates. ${ }^{1617}$ 


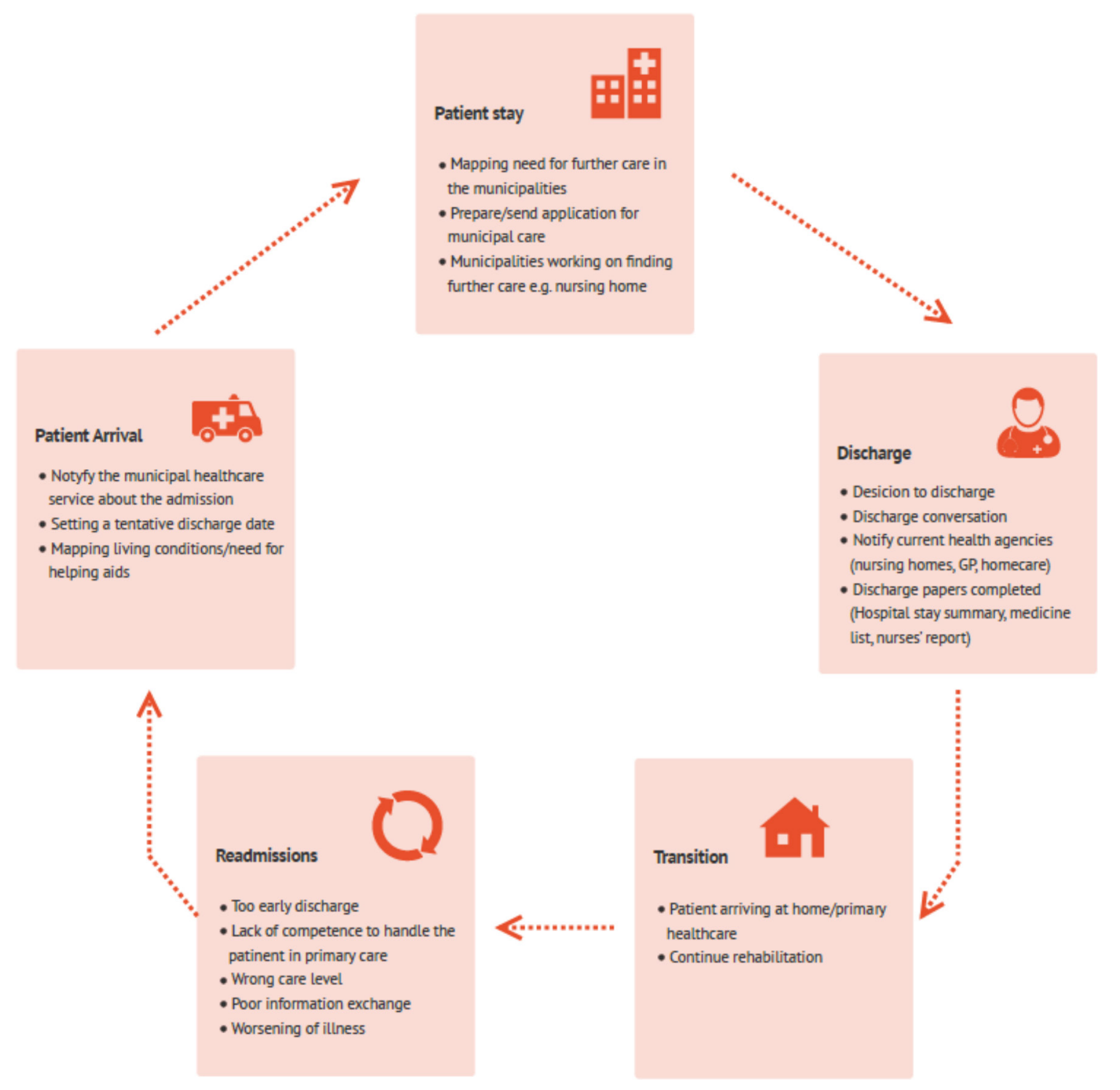

Figure 1 The hospital discharge process.

Different ways of overcoming risks in care transitions and reducing readmissions may exist worldwide. In Norway, the Coordination reform was an attempt to provide seamless transitions by obligating all municipalities responsible for the provision of primary healthcare services to form cooperative agreements with their respective health trusts. ${ }^{18}$ These agreements must stipulate who is responsible for healthcare tasks and state guidelines for cooperative efforts in hospital admissions, discharges and rehabilitation. They must also outline cooperative processes for patients who are ready for hospital discharge but in need of further primary healthcare services (eg, nursing home, home care service and primary care physicians) in a municipality. ${ }^{19}$

Hospital readmissions, hospital discharges and transitional care have previously been well investigated. However, most of the research have separated the three entities, and examined them at each level of the healthcare service. ${ }^{20-23}$ For example, factors affecting hospital readmissions have been explored within the realm of primary healthcare services (eg, nurse turnover, nurse staffing and performance and care quality $)^{24-26}$ or secondary healthcare services (eg, staff responsiveness, length of stay and medication-related events). ${ }^{27-29}$

In two previous studies of hospital readmissions, we found that patients with more complex medical conditions were discharged from the hospital earlier, increasing the responsibilities of primary care physicians (eg, nursing home physicians and GPs) and creating a need for increased competence among the primary care nursing staff. However, nurse competence varied within the primary healthcare services, as did physician staffing and experience. Cooperation and information exchange between the hospital and the primary healthcare services in the municipalities were both seen as insufficient, especially during the discharge process. ${ }^{70}$

To paint a more comprehensive picture of hospital readmissions from primary healthcare services, we explored the discharge process from the hospital physicians' perspective and investigated their views on hospital 
readmissions from the primary healthcare service. Knowledge about the discharging physicians' views on the primary healthcare service to which a patient is being discharged as well as how factors of primary healthcare and the discharge process affect hospital readmissions could be helpful in understanding the overall process of hospital readmissions.

\section{Context}

Norway has a primary healthcare service (eg, nursing homes, home care service and GPs) and a secondary healthcare service (eg, hospitals and psychiatric facilities); each with separate sources of funding. Norwegian municipalities, which are geographically limited areas or communities with some degree of independence from higher government bodies, ${ }^{31}$ are by law responsible for ensuring primary healthcare services for their citizens. The Norwegian state has the main responsibility for secondary healthcare services through four regional health trusts, which are responsible for running the hospitals within their respective regions. ${ }^{32}$ Improving the cooperation and coordination between the two services has been an important governmental goal for the past decade. Efforts to ensure holistic patient care culminated in the introduction of the Coordination reform in 2012. ${ }^{33}$

The Coordination reform includes target strategies, such as preventive healthcare, earlier treatment and better cooperation, offering the right treatment at the right time and place, and a holistic and coordinated patient-centred healthcare service. ${ }^{34}$ Consequently, more healthcare responsibilities have been transferred from the hospital to the municipalities. ${ }^{35}{ }^{36}$ When a hospitalised patient is assessed as ready for discharge by the hospital physicians, any further responsibility for treatment or rehabilitation lies with the municipality. The municipality has the authority to decide what care services a patient will receive after discharge from a hospital; health professionals in a decision office unit exercise this authority. ${ }^{37}$ If a municipality is not able to provide adequate care at this point, an expense of US $\$ 570$ per day will be levied on the municipality until it can fulfil its obligations. ${ }^{38}$ The overall average length of a hospital stay in the investigated area was 7.3 days in 2018. The average length of stay for patients after being deemed as ready for discharge was 4.1 days in the same year. ${ }^{39}$

Following the Coordination reform, systems for electronic communication were implemented to secure adequate communication between healthcare services. ${ }^{1033}$ Electronic communication is principally nurse-to-nurse communication between the hospital, primary healthcare services (nursing homes or home care personnel) and the decision office. ${ }^{40}$ Hospital physicians use electronic communication when sending hospital stay summaries (HSSs) or outpatient notes to GPs. However, the physicians cannot send these documents electronically to nursing home physicians or nurses. There are multiple reasons for this: The establishment of electronic documentation and communication has been a governmental goal connected to the Coordination reform. ${ }^{41}$ However, finding suitable solutions for all communication lines has been a process that is not yet complete. ${ }^{42}$ In Norway, there are over 400 different municipalities, all of which have their own documentation systems. Moreover, physician staffing arrangements vary between nursing homes (eg, regular nursing home physicians may be available during office hours but not weekends; several GPs may share nursing home tasks; different nursing home wards may have different physicians). It is therefore difficult for a hospital physician to know which nursing home physician should receive the HSS. Additionally, there are usually no common electronic addresses for a nursing home, so the HSS needs to be addressed to a specific physician. Consequently, patient HSSs are sent to the GP who is responsible for coordinating their ongoing care. A temporary solution for sending short messages between a primary healthcare service and a hospital has been introduced in some parts of the healthcare system, pending a national scheme. ${ }^{43}$

\section{AIM OF THE STUDY}

The aim of this study was to explore hospital physicians' views on the readmission and discharge processes for elderly patients in the interface between the hospital and municipalities. The following research questions guided our study:

1. What factors inside and outside the hospital do hospital physicians believe affect the hospital discharge process?

2. How do hospital physicians reflect on reasons for hospital readmissions?

\section{METHODS}

\section{Study design}

This study was conducted in accordance with Yin's description of case study research, ${ }^{44} 45$ and it explored hospital readmissions from a primary care perspective. ${ }^{730} \mathrm{~A}$ case was defined as a municipality and an affiliated hospital. Two municipalities were included. The study focused on readmissions from the perspective of physicians working at the hospital that served the two included municipalities. Standards for reporting qualitative research (SRQR) guidelines (see online supplementary file 1) were used in this article. ${ }^{46}$

\section{Sample and recruitment}

Fifteen hospital physicians from different medical and surgical fields (table 1) in a medium-sized Norwegian hospital were recruited. Eligible participants were either consultants or residents involved in both the treatment and the discharge of patients, working in wards with a large proportion of elderly patients. Physicians working in wards where involvement with elderly patients was limited (eg, paediatric wards or maternity wards) were not invited to participate in the study. The hospital physicians were 
Table 1 Overview of included physicians

\begin{tabular}{llllll}
\hline & \multicolumn{2}{l}{ Medical ward } & & \multicolumn{2}{l}{ Surgical ward } \\
\cline { 2 - 3 } \cline { 5 - 6 } & Fellow & Resident & & Fellow & Resident \\
& $\mathbf{6}$ & $\mathbf{3}$ & & $\mathbf{5}$ & $\mathbf{3}$ \\
\hline $\begin{array}{l}\text { Years of } \\
\text { experience }\end{array}$ & $18-38$ & $1-3$ & & $5-28$ & $1-3$ \\
\hline
\end{tabular}

recruited with help from the hospitals' administrative staff (Coordination consultant). In addition, snowball sampling was used because recruited hospital physicians encouraged their colleagues to participate. Some physicians were recruited through social networks and personal contacts. ${ }^{47}$ Two physicians volunteered to participate after an oral presentation of the study was given at a morning meeting.

\section{Data collection}

Semistructured interviews were conducted with 15 hospital physicians between August 2018 and January 2019. Each interview took approximately $30 \mathrm{~min}$, depending on participant responses. The interviews covered several subjects in an interview guide (see online supplementary file 2), and the participants were informed prior to the interviews that the study targeted elderly patients. The interviews were audio recorded and transcribed by the first author. Saturation assessment during the data collection period included a valuation of the adequate sample size for our aim, each participant's information power (participants had characteristics highly specific for our aim, and our various recruitment methods led to the inclusion of participants with a range of experiences) and the quality of dialogue during each interview (most interviews were rich in information and the interviewer had had previous experience with the healthcare service). ${ }^{48}$ We further evaluated the interview content at the end of the interview period, and we made certain that little or no new information was added. We continued with two more interviews to ensure that a correct decision had been made about achieving saturation.

\section{Data analysis}

The interview data were analysed according to Graneheim and Lundman's approach to content analysis, where the unit of analysis (the transcribed interviews) was divided into meaning units, condensed, coded and sorted into subcategories, categories and themes. ${ }^{49}$ We used the analysis programme NVivo 12 Pro at the lower analysis levels (extracting meaning units, coding and enunciating of subcategories). MKG read through the interviews several times, highlighting and sorting relevant meaning units. TK, OR and SW read through the interviews separately to get an overview of the content. Initially, tentative codes were generated to help sort the data material into different units. These codes were changed and reorganised several times during the analysis process to give a suitable overview of the data material. The higher abstraction levels (categories and themes) were analysed manually. The codes and meaning units were copied into a Microsoft Word document and organised in tables. The meaning units were condensed and translated into English. The reorganisation of meaning units and codes continued until they were all sorted adequately. Subcategories emerged during this process, and they were also reorganised several times. Two versions of the coding were sent to TK, OR and SW for discussion and provided a basis for a consultation on the most appropriate solution. During this process, thoughts about possible themes emerged. MKG wrote several summaries in an attempt to understand the underlying meaning of the data material (latent content) ${ }^{50}$ and also brought in an outsider to provide an alternative view of the content. Suitable themes were discussed among all the authors. The analysis of the data material resulted in three main themes (an example of the analysis process of theme 1 is shown in table 2).

In addition to the interview data, central elements from the Commissioner's documents for the Regional Health Authorities from 2012 to 2018 (113 pages) were downloaded and extracted. These documents are publicly available on the internet, are issued once a year and contain requirements from the Ministry of Health and Care Services pertaining to the tasks that are to be carried out in the following year. The Commissioner's documents have two main purposes: to set management requirements for the regional health authorities and to formally make available funds from the Parliament's budget decisions to regional health authorities. ${ }^{51}$

The downloaded documents were analysed to provide a sound contextual understanding and to identify requirements stated in the interface between the hospital and municipality concerning hospital readmissions and the discharge processes.

The main features found in the Commissioner's documents were that there should be established holistic patient care pathways and a clear distribution of tasks between the health trust and municipalities. Healthcare services should offer patients similar or better services than those offered prior to the Coordination reform, which would require close cooperation among the health trusts, the municipalities, the patients and the patients' next of kin. The healthcare services should be restructured to synchronise patient flow between the two levels, and the intention was to implement the changes when municipalities were ready. The health trusts were tasked with offering support and supervision to the municipalities so that they could provide healthcare services in accordance with laws, regulations and agreements.

\section{Patient and public involvement}

No patients, patients' next of kin or healthcare personnel other than physicians participated in this study. 


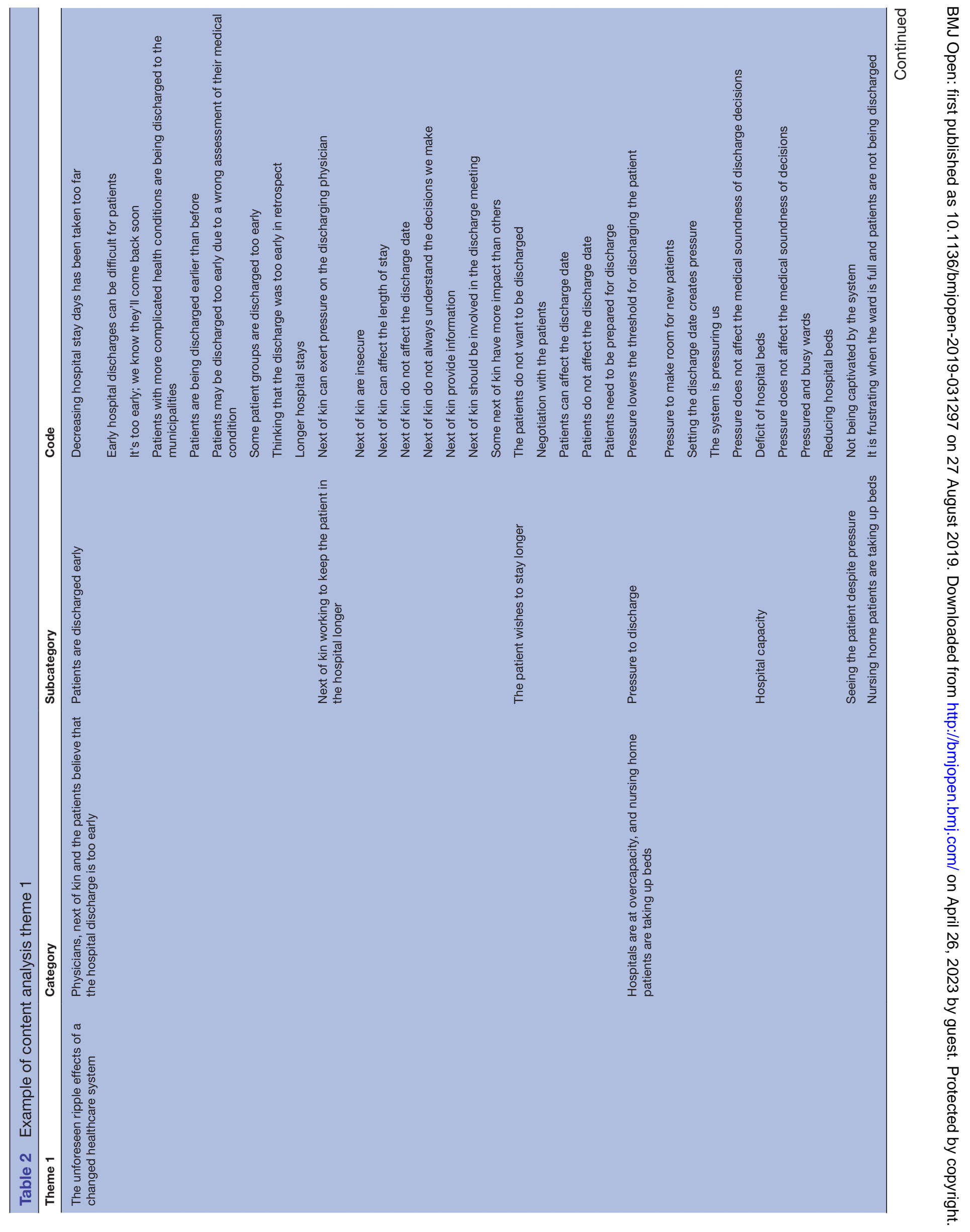




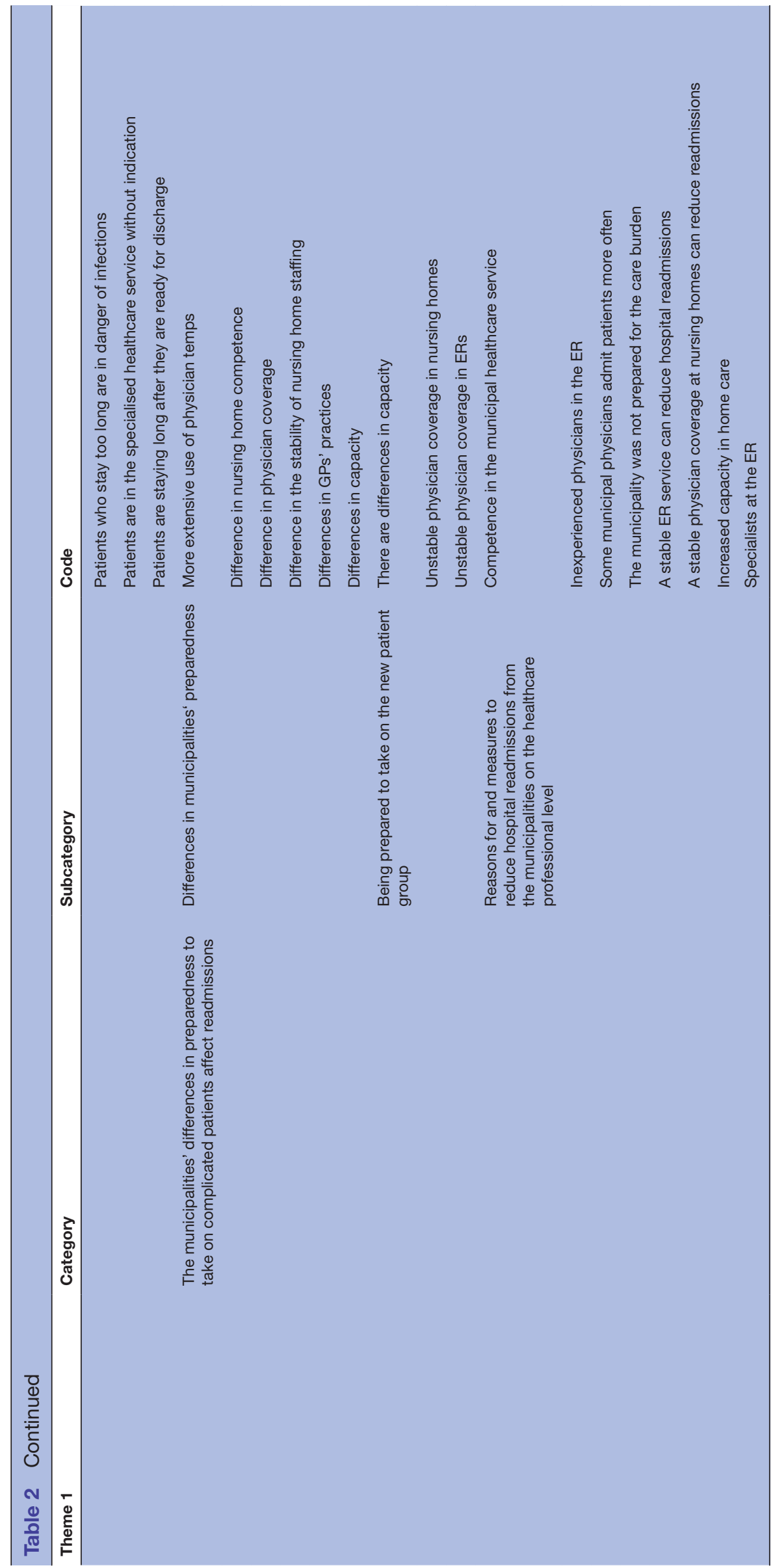




\section{RESULTS}

Overall, the hospital physicians believed that patients were being discharged too early, setting up a situation which, in their opinion, could lead to hospital readmissions. Patients and patients' families could in some cases attempt to prolong a hospital stay to avoid discharge on the scheduled date. Criteria for medically acceptable discharges had changed as a consequence of the Coordination reform. Patients with more complicated health conditions were being discharged to primary care earlier now instead of continuing hospitalisation, and there were limitations in the hospital's capacity to admit new emergency patients, which put pressure on the physicians to discharge patients. At the same time, municipalities were not always able to take on patients who were ready for discharge, causing patients to overstay in the hospital. The physicians detected differences in preparedness between primary healthcare services in taking on complicated patients (staffing, competence and capacity). HSSs were perceived to be the most important aspect of the dialogue between healthcare service levels, and thoroughness in generating the HSSs was seen as important. Other types of dialogue were limited. Hospital discharges involved different healthcare personnel, were affected by several factors and needed careful planning. In the following text, we present the findings on our three themes.

\section{T1: the unforeseen ripple effects of a changed healthcare system \\ Early hospital discharges}

A large proportion of the participants found hospital discharges to be too early and considered them a reason for hospital readmissions. The hospital discharges were described as sometimes being 'on the edge,' especially for elderly patients with chronic diseases. Some claimed that there were too many early hospital discharges and that patients were not being kept long enough in the hospital. According to one physician:

We discharge them too soon, really... And you know they'll come back sooner or later. The patients say so themselves: 'You discharge us too soon; we'll be back in five days anyway'... Resident, medical ward

The patients being discharged to primary care were described as having more complicated health issues than such patients in the past, and the criteria for medically acceptable discharges had changed. Sometimes patient's family members pressured physicians to prolong the hospital stay because they did not feel ready to take care of the patient at home. In addition, according to the hospital physicians, patients, especially elderly ones, did not always want to be discharged on the scheduled date. The physicians described negotiating the discharge date with these patients and stressed the importance of preparing patients for the discharge day to avoid shocking or angering them. The patients' opinions did affect physicians' decisions to discharge; it was easier to let patients stay longer if there was room in the ward.
Disagreement about care decisions

There appeared to be a conflict between decision makers in the municipalities (the decision office) and hospital physicians in regard to what level of care would be needed following hospital discharge. Physicians had a certain level of understanding about the capacity issues in the municipalities, and some believed that the responsibility for allocation rightly rested with the municipality. Several physicians reported that they perceived the care levels offered to patients after discharge to be unsatisfactory. Further, they believed that they had little or no influence in care decisions and sometimes sensed that their assessment of the patient's condition had been overruled, despite the fact that the physicians had direct contact with the patients and had observed them closely. This could result in them keeping patients hospitalised longer, to ensure their safety.

Sometimes we have to take into account... if the municipality offers home care, and we perceive the patient as in need of a nursing home placement, it happens that we keep the patients here longer... we can't justify sending them home with home care services. It's not the way it's supposed to be... Consultant, medical ward

\section{Hospital capacity}

The physicians described the limits of hospital capacity, with too few beds and too many 'hallway patients' (for whom beds had been placed in a hallway because all rooms were full). Full hospital wards create a pressure to discharge patients in order to free up beds for incoming patients. The nurses were described as exerting the most pressure to have patients discharged. They were responsible for the organisation of the ward, including making beds available so they could handle incoming patients. Moreover, physicians felt pressured to schedule a discharge date on the day that a patient arrived, and by the management who wanted to keep hospital stays short and live up to national guidelines. Some described this pressure as a force that caused them to adjust the threshold for when they perceived it reasonable to discharge a patient. Others reported that medical justifiability was not compromised but that it would have been better for patients to stay a few extra days.

The patients get, so to speak, squeezed out right after they are off the CPAP [continuous airway pressure to ease breathing] treatment or the NIV [non-invasive ventilation - breathing support] treatment, and they can get up on to their own feet and can chew and all that, but the anxiety hasn't quite let go, and their infection hasn't quite let go either. Consultant, medical ward

\section{Primary care capacity and preparedness}

The hospital physicians noted that the municipalities were not always able to take on patients who were ready 
for discharge and needed nursing home placement. This resulted in nursing home patients who did not need specialised healthcare taking up beds. These patients sometimes stayed unnecessarily for days and often demanded much in the way of resources because they needed extensive care. This combination of a hospital population of nursing home patients and overflowing wards created frustration. Physicians worried that the hospitalised patients could get infections and then would need to prolong their stay even more.

We had a patient here before Christmas, admitted for pneumonia. He was supposed to be discharged to [primary care], and waited here [at the ward], for a week. Then he caught pneumonia again, and we had to cancel the discharge and start up treatment again. When he was treated [for the second time], he overstayed for another week - [got a] new pneumonia. It continued like this for six weeks, so he had pneumonia four times... Resident, medical ward

The physicians detected variations in the municipalities' ability to take on patients in need of nursing home placements. In addition, they perceived a variation in the primary healthcare service's preparedness to provide care for these complicated patients. The physicians also saw differences in primary healthcare physician coverage and competence, in nurse competence and in primary care capacity. These were regarded as reasons for hospital readmissions from the municipalities, with a special concern about inconsistent physician coverage in nursing homes and emergency rooms (ERs). For instance, some described the ER as a 'substitute service,' with a lack of capacity for proper follow-up care and run by inexperienced physicians who were unfamiliar with the healthcare system. The physician coverage in nursing homes was described as inconsistent, and holistic follow-up care was perceived as difficult to organise.

The hospital physicians suggested that stable ER services, stable physician coverage and an increased capacity in homecare and nursing home services could reduce the number of hospital readmissions.

\section{T2: a vulnerable communication line between cooperating healthcare services \\ Communication between healthcare services}

HSSs were the most important, and sometimes only, form of communication between the hospital and the primary healthcare services. Concise HSSs were highlighted as important and influential in hospital readmissions. However, some difficulties with using the HSSs for communication were reported. HSS was routinely sent to a GP when it was completed, but if a patient was going to a nursing home, where the patient would be under the supervision of a different physician, there was no guarantee that the summary would reach that physician.

Our routine is to send the hospital stay summary to the GP, even if they are going to a nursing home.
In addition, we send a copy with the patient. But if the [nursing home] physician in charge is not present, and it is not the GP [who is the nursing home physician], the physician won't get the papers. (...) Resident, surgical ward

It could also be challenging for a physician with a heavy patient load to finish the HSS prior to the hospital discharge. Some days, a physician would have as many as five discharges, each requiring an HSS, and the physician may have needed to write prescriptions and make outpatient clinic appointments in addition to other daily tasks. A heavy workload was also a reason for the limited contact between the hospital and the primary healthcare services, including the difficulty in reaching GPs by telephone during office hours. Some physicians were satisfied with the amount of contact they had with primary care physicians, but others would have liked more communication and cooperation, especially when they were dealing with complicated patients or those needing medication changes.

The results showed a lack of good communication tools. Some wards had access to an electronic messaging system enabling communication between the GP and the hospital physician. Most of the respondents had never heard of this system and noted that it would be useful. The wards that did use it reported differences in how often various GP offices took advantage of it. Nursing home physicians had no access to the system. Furthermore, reading and replying to messages was a low priority when there were many other things that needed to be done.

\section{Communication, cooperation and hospital readmissions}

Several physicians argued that improved communication and cooperation between the healthcare services could reduce hospital readmissions. Some suggested the creation of a shared documentation system, where the primary care and hospital physicians could have access to each other's notes, the records of medication changes and the nurses' reports. One physician said:

If the nursing home physician can enter [our documentation program] and see what has already been said, which medication has been discontinued and approved, and can continue the treatment we have started here, we don't have to write it up [in another document] and waste everyone's time. And [it's] the same when they come back [to the hospital]; we don't have any information either! The interns tell me they spend $40 \mathrm{~min}$ filling out the medication list. Consultant, medical ward

The hospital physicians further suggested that the primary care physicians should contact them more for advice and consultation to increase communications and decrease hospital readmissions. Despite difficulties with getting in touch with the right hospital physician, this contact was the most common point of dialogue after HSSs. 
T3: hospital discharges is an intricate process

\section{Decisions to discharge involve several steps}

Hospital discharges were reported to be affected by numerous factors, requiring several planning steps and the input of numerous healthcare workers. Medical assessment was the essential factor in discharge decisions, including the assessment that the patient no longer needed further specialised treatment. A non-medical factor was the type of care the patient was going to need following discharge. If the treatment could be continued in the primary healthcare service, it could lead to an earlier hospital discharge. Some physicians reported that they made sure that continuation of care in the primary healthcare service was possible, whereas others expected the receiving institution to have the competence needed to handle a discharged patient. The patients' functional level and ability to engage in self-care at home were also considered in the decision.

The discharge decision was made by a team of health personnel, such as consultants, residents, nurses, physiotherapists and occupational therapists. The nurses were obviously extensively involved because they had comprehensive knowledge about the patient's functional level. Residents described involving consultants for complicated patients. After regular business hours, however, residents were often left alone to make these decisions. Time constraints could limit the ability to perform multidisciplinary assessments before discharge.

Occasionally, one can be a bit quick to write, 'is to be followed up by the GP.' Sometimes if it is very busy, it happens that we point out in the hospital stay summary 'further assessment by the GP.' But the ideal would be to, sort of, remove that link and refer the patients ourselves. Maybe after a phone call with a geriatrician or something. For it to go a bit faster. Resident, surgical ward

\section{The discharge process and hospital readmissions}

The discharge process was seen as closely related to hospital readmissions. Physicians insisted on the importance of proper discharge planning, ensuring that the patient was capable of self-care following hospital discharge and scheduling a follow-up appointment. One physician stated that it would be an advantage to know more about the offerings in the primary healthcare services. Another physician claimed that increased use of outpatient clinics had reduced hospital readmissions in their ward. A third physician suggested that some sort of transitional care, between a hospital and a nursing home, would be an advantage (eg, a ward for oncology patients staffed by experienced nurses).

\section{Not all hospital readmissions should be avoided}

There was a consensus that many hospital readmissions were necessary. Avoiding hospital readmissions was not always a desirable end in itself. There could be fluctuations in the course of an illness, complications or simply a deterioration of a patient's condition that would mandate specialised treatment. One physician stated that hospital readmissions were sometimes encouraged because physicians wanted to perform their own assessments before starting, for example, antibiotic treatment.

\section{DISCUSSION}

The discharge process and the decision to discharge were described as complex processes involving several people (eg, the patient, the patient's family, nurses and physicians). Although medical considerations had first priority, organisational factors both within and outside the hospital also affected the decisions. Within the hospital, early hospital discharges and a poor communication system were perceived to affect hospital readmissions. Primary care capacity, primary care competence and unstable physician coverage in nursing homes and ERs were factors affecting hospital readmissions outside the hospital. In the interface between the hospital and the primary healthcare services, poor communication and a lack of cooperation were perceived to be the main reasons for hospital readmissions.

\section{Early hospital discharges}

According to the regulations, ${ }^{52}$ a patient who has been assessed by hospital physicians as no longer in need of hospital treatment is ready for discharge. The assessment should include current or emerging medical issues, diagnostic issues, recommendations for further treatment and a description of the patient's overall level of functioning. In the current study, several additional factors were found to influence the physicians' assessments, such as management oversight of hospital stays, the discharge date and access to primary healthcare services following hospital discharge. The literature has previously described physicians' concern about early hospital discharges leading to hospital readmissions. ${ }^{30}$ Although there is limited documentation of a direct relationship between the two, the preparedness of primary healthcare services to care for patients with complicated health issues has been discussed, ${ }^{53}$ indicating that such concerns are of relevance.

\section{Disagreements on care level post hospital discharge}

Consistent with existing literature, disagreement in care level after hospital discharge was described here. ${ }^{737}$ Physicians in our study perceived discrepancies between their close knowledge of the patient and their lack of influence in such decisions with some physicians in our study reporting that they kept patients a few days longer if they found that the decision on care level was unsatisfactory. La Rocca and Hoholm ${ }^{37}$ examined the role of Decision officers in disagreements on care level post hospital discharge. Decision officers in this study were mostly concerned with formal rules in these cases, substantiating the role that office authorities play in care decisions. Hospital physicians who suggested care following hospital 
discharge were perceived as problematic by decision officers. ${ }^{37}$ The perceptions of physicians and decision officers indicates a difficult relationship between the two parties, contradicting one of the main purposes of the Coordination reform. However, the reasons for these differences in assessments are poorly explained and merit further investigation. Including the views of nurses and other health personnel involved in patient care would be beneficial in this regard.

A newly published Norwegian report investigating accessibility and quality of care for the elderly found that decision officers often lacked relevant information about a patient's functioning, wishes and needs when making care decisions, resulting in poorly justified decisions. ${ }^{52}$ Further, sometimes, decisions seem to have been affected by the decision officers' personal factors; so decisions could vary within municipalities and between different municipalities. This supports our finding that there are differences among municipalities in the allocation of primary healthcare services, something that is potentially inconsistent with the hallmark of the Norwegian welfare state: equal rights to welfare benefits.

\section{Pressure on healthcare services}

A new report of Norwegian hospitals stated that approximately 46000 patients were overstaying for at least 24 hours after being assessed as ready for discharge in $2018 .^{54}$ This was an increase of 5000 patients from 2017 , indicating that overstays remain an ongoing national problem. This problem, which places even more pressure on wards, is also described in our results.

Despite the increased patient load in the municipalities, there has been a minimal increase in primary care resources. ${ }^{55}$ With this in mind, it can be questioned if the pressure on primary healthcare service resources is clouding the assessment on post hospital discharge care, implying incorrect care assessments and consequently more hospital readmissions. Nevertheless, the results of this study describe a complex web of interacting elements in the two healthcare services, caused mainly by the regulations of the Coordination reform. This has some identified undesirable consequences for both the primary healthcare service and the hospital (figure 2).

\section{Communication between healthcare services}

The information exchange system between the primary and secondary healthcare services was fragile, especially for nursing home patients. Previous research supports these findings, reporting poor routines in forwarding information to nursing home physicians ${ }^{56}$ Consistent with existing literature, the physicians in our study believed that poor communication could lead to hospital readmissions. ${ }^{575}$ The hospital physicians believed that a common documentation system could resolve these difficulties. Such a system has shown to improve the quality of care and access to clinical information, decrease healthcare costs and reduce hospital readmissions, ${ }^{5960}$ or physicians believe it has this effect. ${ }^{761}$ In 2015 , the National Network for Implementation of the Coordination reform recommended a common documentation system. ${ }^{41}$ Although it has been a governmental goal since $2012,{ }^{62}$ as of 2019 , most hospitals still do not have it. ${ }^{42}$

\section{Work as imagined and work as done}

The Commissioners' documents require hospitals to establish holistic care pathways, with a clear distribution of tasks between healthcare services. In order to achieve this, close cooperation between all the relevant parties (patient, hospital and the primary healthcare service) is encouraged. However, according to our results, changes have not been made in the system that might fulfil these requirements. For example, there continues to be a lack of communication tools, a lack of a common documentation system and insufficient time for cooperation. This indicates a gap between the requirements of the Commissioners' documents and the current work practice.

This gap is closely related to the terms work-as-imagined (WAI) and work-as-done (WAD) in the resilience healthcare literature. ${ }^{63}$ Hollnagel $^{64}$ describes WAI as an idealised view of how tasks should be performed in a system, where there is an assumption that work tasks can be completely analysed and prescribed, as, for example, has been done in the Commissioners' documents. However, in reality, where the tasks are being performed, conditions are constantly changing (eg, in workload), creating a discrepancy between the WAI and WAD. ${ }^{64}$ In relation to the Commissioners' documents, the results from the current study suggest that the context in which care decisions are made has not been considered. This could be related to an exclusion of healthcare workers from the formulation of these requirements. Similar gaps can also be seen in the Coordination reform, the main goals of which have shown difficult to fulfil and where there have been unforeseen consequences of organisational changes. Figure 2 illustrates the WAD in accordance with our results, and figure 3 depicts the WAI according to the aims of the Coordination reform, demonstrating the complexity of the WAD compared with the WAI in a small cross section of the Norwegian healthcare system. A possible way to close the gap between the WAI and WAD could be to invite more health personnel to contribute to the development of such requirements. We believe that such an approach may lead to requirements that are closer to practice and to the possibility of adjusting practice (eg, providing better tools) to meet the requirements.

\section{Suggestions for future interventions}

There have been reports of several successful interventions developed to reduce hospital readmissions. For example, the Hospital Readmissions Reduction Program (HRRP), introduced to American hospitals in 2012, aimed to reduce readmission by reducing hospital payments with excess readmissions. HRRP has been shown to have a positive but limited effect on hospital readmission rates, depending on the current patient group. ${ }^{65-67}$ Other hospital-based interventions such as the introduction of 


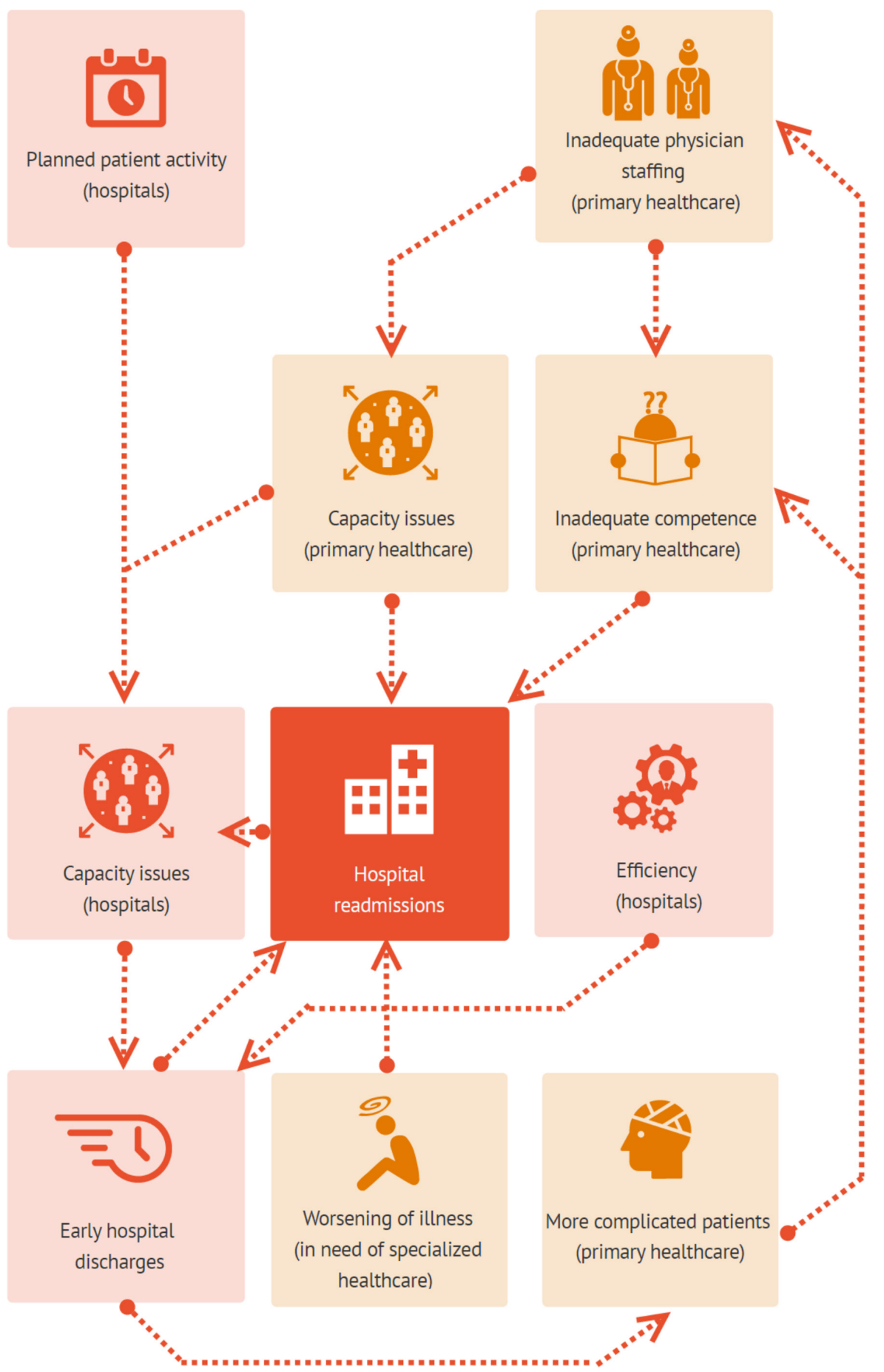

Figure 2 Work as done.

discharge protocols (medication reconciliation, scheduling of appointments after discharge ${ }^{8}$ and nurse-led telephone follow-up) have been shown to reduce hospital readmissions. ${ }^{68}$ Interventions in primary care have also been demonstrated as successful (eg, skilled training for nurses in long-term facilities ${ }^{69}$ and readmission reduction tools for nursing home personnel ${ }^{70}$ ). Our study provides a foundation for targeted interventions in Norway by identifying problems that healthcare workers find predictive of hospital readmissions (eg, early hospital discharges; preparedness, competence and capacity in the primary healthcare services; and poor communication and coordination). More research on the possibility of implementing interventions used elsewhere in a Norwegian context could be useful.

\section{Limitations}

The limitations of the current study are primarily methodological. The physicians in our study had a tight work schedule and were, therefore, difficult to recruit. As the audio-recordings of interviews were of high quality with little room for misinterpretation and to reduce extra work 


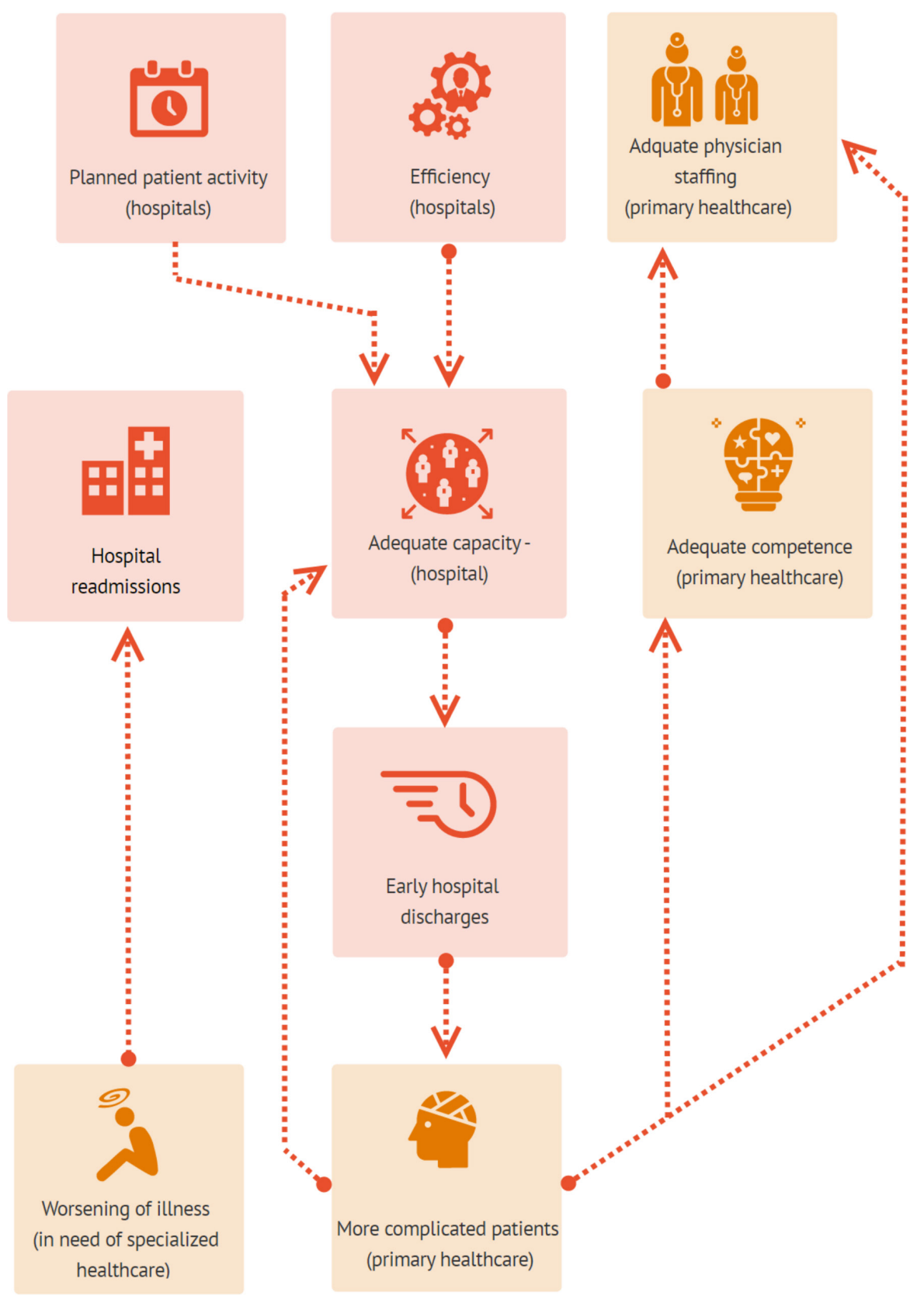

Figure 3 Work as imagined.

for the informants in fear of informants losing interest, we decided not to share the transcripts with the physicians before the analysis process started. Moreover, this decision was based on reports in the literature describing the unclear impact of sharing transcripts with informants. ${ }^{71}$ It is possible that not sharing the transcripts could have led to insufficient validation of data.

The scope of this study included the perspectives of hospital physicians but not patients, nurses or other health personnel working in hospital wards. Their inclusion could have provided important perspectives on the discharge process and hospital readmissions from the municipalities. On the other hand, focusing only on interactions with primary healthcare services allows for more precise results. In case study research, bounding the case is an important term. It is related to distinguishing the right unit of analysis to answer the research question from other groups within a case. ${ }^{45}$ Bounding the case is important to avoid a scope that is too broad or too narrow. ${ }^{72}$ This paper reports from a case study including three substudies. In this case study, nursing home nurses, nursing home leaders, ${ }^{30} \mathrm{GPs}^{7}$ and hospital physicians (in the current paper) were assessed to fulfil the research aim most successfully. Research on patients, patients' next of kin and nurse perspectives and more focused studies on hospital readmissions should be prioritised in further research.

Lastly, because this study focused on hospital readmissions and discharges of elderly patients, the definition of elderly was important. The participants were informed 
about the focus, but they could have had different perceptions than we did about the definition of elderly. It can also be difficult for the physicians to remember the specific age of a patient when talking about experiences with readmissions and discharges in general. This is a common weakness when collecting lived experiences data in qualitative research. ${ }^{73}$ It could lead to having information about other age groups than elderly persons being included in the data material. However, we believe that the context (interviewing physicians in wards with a large proportion of elderly patients) and the information given them about the scope before the interview resulted in appropriate data.

\section{CONCLUSION AND IMPLICATIONS}

The current study identified a gap between the Commissioner's requirements and Coordination reform regulations and the current practices in municipalities and hospitals. The results give a broader understanding of hospital physicians' views of the discharge process and hospital readmissions in the interface between the hospital and the primary healthcare service. We recommend improved communication systems and more shared decision-making processes between service levels as a way of improving dialogue and sharing knowledge and expertise to reduce the number of unnecessary readmissions and ensure that each patient is transferred after discharge to a proper level of care. This may imply the use of shared time for healthcare professionals in hospitals and the primary healthcare services. Based on our results, this would be likely to reduce pressure on the system and on patients caused by unnecessary overstays, readmissions or the reception of an inappropriate level of care after discharge. Future research should look to test and improve care coordination from a multilevel perspective, including patients as key stakeholders. ${ }^{74-76}$

Acknowledgements The authors want to thank the participating physicians for their contribution to the study and the hospitals' coordination consultant for help in the recruitment of informants. Further, we would like to thank Ole-Jørn Borum for the graphic design of figures 1 to 3 , Dr Elizabeth Austin from the Australian Institute of Health Innovation (AlHI) for proof reading and contributing to language quality improvement and the reviewers of BMJ Open for helping us to improve our manuscript with valuable comments and questions.

Contributors MKG contributed to the study design; submitted the ethical approval application; collected, analysed and interpreted the data; and was the main contributor in the writing and revision of the manuscript. TK and OR contributed to the study design, guided the data analysis and assisted with writing and revising the manuscript. SW contributed to the study design, supervised the project, guided the analysis and was a major contributor to the writing and revising of the manuscript. All authors have approved the final manuscript.

Funding The implementation and publication of this study is funded by the Western Norway University of Applied Sciences.

Disclaimer The funding body was not involved in the research process (design of the study, data collection, analysis or interpretation of data) or in writing the manuscript.

Competing interests None declared.

Patient consent for publication Obtained.

Ethics approval The study has been approved by the Norwegian Center for Research Data (NSD) (Reference number: 49331, Date: 01.08.2016).
Provenance and peer review Not commissioned; externally peer reviewed.

Data availability statement Data are available upon reasonable request.

Open access This is an open access article distributed in accordance with the Creative Commons Attribution Non Commercial (CC BY-NC 4.0) license, which permits others to distribute, remix, adapt, build upon this work non-commercially, and license their derivative works on different terms, provided the original work is properly cited, appropriate credit is given, any changes made indicated, and the use is non-commercial. See: http://creativecommons.org/licenses/by-nc/4.0/.

\section{REFERENCES}

1. van Galen LS, Brabrand M, Cooksley T, et al. Patients' and providers' perceptions of the preventability of hospital readmission: a prospective, observational study in four European countries. BMJ Qual Saf 2017;26:958-69.

2. Auerbach AD, Kripalani S, Vasilevskis EE, et al. Preventability and causes of readmissions in a national cohort of general medicine patients. JAMA Intern Med 2016;176:484-93.

3. Rasmussen MG, Ravn P, Molsted S, et al. Readmission to hospital of medical patients - A cohort study. Eur J Intern Med 2017;46:19-24.

4. Skyrud KD, Kristoffersen TD, Hansen TM. 30 dagers overlevelse OG reinnleggelse etter sykehusinnleggelse. Resultater for 2017 (English title: 30 day survival and readmission after hospital admission. Results for 2017). Norwegian Institute of Public Health, 2019.

5. Hekkert K, Borghans I, Cihangir S, et al. What is the impact on the readmission ratio of taking into account readmissions to other hospitals? A cross-sectional study. BMJ Open 2019;9:e025740.

6. Hesselink G, Zegers M, Vernooij-Dassen M, et al. Improving patient discharge and reducing hospital readmissions by using intervention mapping. BMC Health Serv Res 2014;14:389.

7. Glette MK, Kringeland T, Røise O, et al. Exploring physicians' decision-making in hospital readmission processes - a comparative case study. BMC Health Serv Res 2018;18.

8. Simorangkir H, McGuire SJJ. Training in readmission reduction in an Indonesian Hospital. Hosp Top 2017;95:40-50.

9. Laugaland K, Aase K, Waring J. Hospital discharge of the elderly-an observational case study of functions, variability and performanceshaping factors. BMC Health Serv Res 2014;14:365.

10. Directorate of Health. Tiltakspakke for trygg utskrivning Med pasienter SOM likeverdig part (English title: measures for safe discharge with patients as equal parties), 2017.

11. Aase K, Laugaland KA, Dyrstad DN, et al. Quality and safety in transitional care of the elderly: the study protocol of a case study research design (phase 1). BMJ Open 2013;3:e003506.

12. Ohta B, Mola A, Rosenfeld P, et al. Early discharge planning and improved care transitions: pre-admission assessment for readmission risk in an elective orthopedic and cardiovascular surgical population. Int J Integr Care 2016;16:10.

13. Helse og Omsorgsdepartementet. In: omsorsdepartementet Ho, ed. Kvalitet OG pasientsikkerhet. Oslo, 2014-2015.

14. Kvalitet og pasientsikkerhet 2015 (English title: Quality and patient safety 2015), Meld.st.14 (2016 - 2017), 2016.

15. Leve hele livet : en kvalitetsreform for eldre, 2018.

16. Abelsen B, Gaski M, Nødland SI, et al. Samhandlingsreformens konsekvenser for det kommunale pleie-og omsorgstilbudet (English title: the repercussions of the cordination reform for the municipal care and care provision). International research Institute of Stavanger (IRIS) 2014. Contract No.: 7252370.

17. Huseby BM, Tønnesen CN, Snøfugl G, et al. Samhandlingsstatistikk 2014-2015. Oslo: Norwegian Directorate of Health, Helsedirektoratet, 2015.

18. Act on municipal health and care services§, 2011:6-1.

19. Cooperation agreement between the health trust and municipality $A$, 2017.

20. Connolly M, Grimshaw J, Dodd M, et al. Systems and people under pressure: the discharge process in an acute hospital. $J$ Clin Nurs 2009;18:549-58.

21. King BJ, Gilmore-Bykovskyi AL, Roberts TJ, et al. Impact of hospital context on transitioning patients from hospital to skilled nursing facility: a Grounded theory study. Gerontologist 2018;58:521-9.

22. Ofoma UR, Dong Y, Gajic O, et al. A qualitative exploration of the discharge process and factors predisposing to readmissions to the intensive care unit. BMC Health Serv Res 2018;18:6.

23. Bench S, Cornish J, Xyrichis A. Intensive care discharge summaries for general practice staff: a focus group study. Br J Gen Pract 2016;66:e904-12.

24. Thomas KS, Mor V, Tyler DA, et al. The relationships among licensed nurse turnover, retention, and rehospitalization of nursing home residents. Gerontologist 2013;53:211-21. 
25. Pandolfi MM, Wang Y, Spenard A, et al. Associations between nursing home performance and hospital 30-day readmissions for acute myocardial infarction, heart failure and pneumonia at the healthcare community level in the United States. Int J Older People Nurs 2017;12:12154.

26. Ogunneye $\mathrm{O}$, Rothberg MB, Friderici $\mathrm{J}$, et al. The association between skilled nursing facility care quality and 30 -day readmission rates after hospitalization for heart failure. Am J Med Qual 2015;30:205-13.

27. Yang L, Liu C, Huang C, et al. Patients' perceptions of interactions with hospital staff are associated with hospital readmissions: a national survey of 4535 hospitals. BMC Health Serv Res 2018;18. 1-N.PAG.

28. Heggestad T. Do hospital length of stay and staffing ratio affect elderly patients' risk of readmission? A nation-wide study of Norwegian hospitals. Health Serv Res 2002;37:647-65.

29. Crispo JAG, Thibault DP, Fortin Y, et al. Association between medication-related adverse events and non-elective readmission in acute ischemic stroke. BMC Neurol 2018;18:192. N.PAG-N.PAG.

30. Glette MK, Røise O, Kringeland T, et al. Nursing home leaders' and nurses' experiences of resources, staffing and competence levels and the relation to hospital readmissions - a case study. BMC Health Serv Res 2018;18.

31. Geir Thorsnæs OTB. kommune store norske leksikon, 2019 Available: https://snl.no/kommune

32. Health and care minestry. De regionale helseforetakene the Norwegian Governement, 2014. Available: https://www.regjeringen. no/no/tema/helse-og-omsorg/sykehus/innsikt/nokkeltall-og-fakta-ny/ de-regionale-helseforetakene/id528110/

33. Health and care minestry. Samhandlingsreformen. Rett behandling på Rett sted - TIL Rett tid, 2009.

34. Health Do. Samhandlingsreformen (English title: the coordination reform), 2018. Available: https://helsedirektoratet.no/ samhandlingsreformen [cited 27 Nov 2018].

35. Lie S. Status for samhandlingsreformen, Forvaltningsmessig følge med-rapport fra Helsedirektoratet juni 2015 (English title: status for the coordination reform, follow-up report from the Directorate of health June 2015). Directorate of Health, 2015.

36. Kristoffersen DT, Moen HT, Schou L A, et al. Kvalitetsindikatoren 30-dagers reinnleggelse etter sykehusopphold 2014 - resultater for sykehus og kommuner 2014 (English title: quality indicator 30-day readmission after hospital stay 2014 - results for hospitals and municipalities). Institute of public health, 2016.

37. La Rocca A, Hoholm T. Coordination between primary and secondary care: the role of electronic messages and economic incentives. BMC Health Serv Res 2017;17:149.

38. Forskrift Om kommunal betaling for utskrivningsklare pasienter (English title: regulations for municipal payment for patients ready for discharge), 2012.

39. Myrli TR, Mortensen SM. Utvikling i liggedager og reinnleggelser for utskrivningsklare pasienter 2012 - 2017 (English title: Development in hospital stay days and readmissions for patients ready for discharge). Directorate of Health, 2018, Contract No.: 5

40. Brattheim BJ, Hellesø R, Melby L. Elektronisk meldingsutveksling ved utksivning AV pasient fra sykehus TIL kommune (English title: electronic message exchange for patients discharged from hospital). Sykepleien Forskning 2016;1:26-33.

41. National network for implementation of the coordination reform. Råd for vegen videre, sluttrapport (English title: advice for the road ahead, final report. Norwegian Ministry of Health and care services, 2015.

42. Ryvarden E. Helse-Norge bør samles under ett IT-system (Health Norway should be gathered under one IT system). From the editor [Internet], 2018. Available: https://tidsskriftet.no/2018/09/fraredaktoren/helse-norge-bor-samles-rundt-ett-it-system [cited 03 Dec 2019].

43. Johannessen JR, meldinger D. meldingsutveksling mellom Fastleger OG Sykehusleger (English title: dialogue messages, message exchange between GPs and hospital physicians). Sydvesten 2017;1.

44. Yin RK. Applications of case study research. 3rd edn. Los Angeles: SAGE, 2012.

45. Yin RK. Case study research: design and methods. 5th edn. Los Angeles, Calif: SAGE, 2014.

46. O'Brien BC, Harris IB, Beckman TJ, et al. Standards for reporting qualitative research: a synthesis of recommendations. Acad Med 2014;89:1245-55.

47. Joseph RP, Keller C, Ainsworth BE. Recruiting participants into pilot trials: techniques for researchers with shoestring budgets. Calif $J$ Health Promot 2016;14:81-9.

48. Malterud K, Siersma VD, Guassora AD. Sample size in qualitative interview studies: guided by information power. Qual Health Res 2015;26:1753-60.
49. Graneheim UH, Lindgren B-M, Lundman B. Methodological challenges in qualitative content analysis: a discussion paper. Nurse Educ Today 2017;56:29-34.

50. Graneheim UH, Lundman B. Qualitative content analysis in nursing research: concepts, procedures and measures to achieve trustworthiness. Nurse Educ Today 2004;24:105-12.

51. Health and care minestry. Oppdragsdokument (English title: Commisioner's documents), 2016. Available: https:// www.regjeringen.no/no/tema/helse-og-omsorg/sykehus/ styringsdokumenter1/oppdragsdokument/id535564/

52. The office of the Auditor General of Norway. Riksrevisjonens undersøkelse AV tilgjengelighet OG kvalitet I eldreomsorgen (English title: the office of the auditor General's investigation of accessibility and quality in elderly care), 2018.

53. Gautun H, Syse A. Earlier hospital discharge: a challenge for Norwegian municipalities. Nordic Journal of Social Research 2017;8.

54. Norwegian Directorate of Health. Utvikling OG variasjon I opphold, liggetid $O G$ andel reinnleggelser for utskrivningsklare pasienter (English title development and variation in residence, length of stay and proportion of re-admissions for patients ready for discharge), 2018.

55. Office of The Auditor General of Norway. Riksrevisjonens undersøkelse AV ressursutnyttelse OG kvalitet I helsetjenesten etter innføringen AV samhandlingsreformen (English title: the auditor General's survey of resource utilization and quality in the health service following the introduction of the coordination reform). Oslo: Office of The Auditor General of Norway, 201612.12. Contract No.: 3:5 (2015-2016).

56. Wibe T, Ekstedt M, Hellesø R. Information practices of health care professionals related to patient discharge from hospital. Inform Health Soc Care 2015;40:198-209.

57. Witherington EMA, Pirzada OM, Avery AJ. Communication gaps and readmissions to hospital for patients aged 75 years and older: observational study. Qual Saf Health Care 2008;17:71-5.

58. Auerbach AD, Kripalani S, Vasilevskis EE, et al. Preventability and causes of readmissions in a national cohort of general medicine PatientsReadmissions in a national cohort of general medicine patients readmissions in a national cohort of general medicine patients. JAMA Internal Medicine 2016;176:484-93.

59. Chen M, Guo S, Tan X. Does health information exchange improve patient outcomes? empirical evidence from Florida hospitals. Health Aff 2019;38:197-204.

60. Park $\mathrm{H}$, Lee $\mathrm{S}-\mathrm{il}$, Hwang $\mathrm{H}$, et al. Can a health information exchange save healthcare costs? Evidence from a pilot program in South Korea. Int J Med Inform 2015;84:658-66.

61. Wright A, Soran C, Jenter CA, et al. Physician attitudes toward health information exchange: results of a statewide survey. J Am Med Inform Assoc 2010;17:66-70.

62. Ministry of Health and Care Services. Én innbygger - én journal Digitale tjenester i helse- og omsorgssektoren (english title: One resident - one journal Digital services in the health and care sector), 2013.

63. Braithwaite J, Wears RL, Hollnagel E, eds. Resilient Health Care. In: Reconciling Work-as-Imagined and Work-as-Done. Vol 3. New York: CRC Press, 2016.

64. Hollnagel E, Robert LW, Braithwaite J. From Safety-I to safety -II: a white paper. University of Southern Denmark, University of Florida, USA, and Macquarie Univeristy, Australia: The Resilient Health care Net, 2015.

65. Lu N, Huang KC, Johnson JA. Reducing excess readmissions: promising effect of hospital readmissions reduction program in US hospitals. Int J Qual Health Care 2016;28:53-8.

66. Ramaswamy A, Marchese M, Cole AP, et al. Comparison of hospital readmission after total hip and total knee arthroplasty vs spinal surgery after implementation of the hospital readmissions reduction program. JAMA Netw Open 2019;2:e194634.

67. Sandhu AT, Heidenreich PA. Comparison of the change in heart failure readmission and mortality rates between hospitals subject to hospital readmission reduction program penalties and critical access hospitals. Am Heart J 2019;209:63-7.

68. Mols RE, Hald M, Vistisen HS, et al. Nurse-Led motivational telephone follow-up after same-day percutaneous coronary intervention reduces readmission and contacts to general practice. $J$ Cardiovasc Nurs 2019;34:222-30.

69. Hovey SL, Kim M, Dyck MJ. Hospital readmission rates following skills training for nurses employed in long-term care facilities. $J$ Nurs Care Qual 2015;30:380-4.

70. Ouslander JG, Perloe M, Givens JH, et al. Reducing potentially avoidable hospitalizations of nursing home residents: results of a pilot quality improvement project. J Am Med Dir Assoc 2009;10:644-52. 
71. Hagens V, Dobrow MJ, Chafe R. Interviewee transcript review: assessing the impact on qualitative research. BMC Med Res Methodol 2009;9:47

72. Baxter P, Jack S. Qualitative case study methodology: study design and implementation for novice researchers. The Qualitative Report 2008;13:544-59.

73. Polkinghorne DE. Language and meaning: data collection in qualitative research. J Couns Psychol 2005;52:137-45.
74. O'Hara JK, Reynolds C, Moore S, et al. What can patients tell us about the quality and safety of hospital care? findings from a UK multicentre survey study. BMJ Qual Saf 2018;27.

75. Aase K, Schibevaag L, Waring J, eds. Researching quality in care transitions international perspectives. Cham: Springer Nature, 2017.

76. Dyrstad DN, Testad I, Aase K, et al. A review of the literature on patient participation in transitions of the elderly. Cogn Tech Work $2015 ; 17$. 